\title{
MENGKAJI PERPUTARAN UANG BANK MELALUI MODEL KALDOR-KALECKI: TINJAUAN NUMERIK UNTUK SISTEM KARTU KREDIT
}

\author{
A. Sehani1 ${ }^{1}$ R. Ratianingsih ${ }^{2}$, dan J. W. Puspita ${ }^{3}$ \\ 1,2,3Program Studi Matematika Jurusan Matematika FMIPA Universitas Tadulako \\ Jalan Soekarno-Hatta Km. 09 Tondo, Palu 94118, Indonesia. \\ 1ayusehani13@gmail.com,2ratianingsih@yahoo.com,3juni.wpuspita@yahoo.com
}

\begin{abstract}
Credit Card is a card payment instrument, where the cardholder's payment obligation is firstly fulfilled by the acquirer or publisher which use third party funds in the form of investments to pay the obligation payment of cardholder. These investment funds are managed as the initial fund of credit card customers. Some of the generated profits could be saved as bank deposits, while others are used for joint capital investment funds. The preview description shows the circulation of bank deposit of the credit card system which mathematically corresponds to the concept represented by Kaldor-Kalecki model. The aims of this study is that money circulation process is represented numerically by such model solution using the Runge-Kutta method. The interpretation of the numerical solution of the Kaldor-Kalecki model of the credit card system is simulated for Bank Mega's financial report data in 2017, the results shows that Bank Mega was found a decline of the number of credit card production. It could be said that the numerical solutions well represented the condition of the credit card system issued by Bank Mega. Negative values of numerical solution also reviews as period of the Bank investment.
\end{abstract}

\section{Keywords $\quad$ : Credit Card, Kaldor-Kalecki Model, Runge-Kutta Method}

\section{ABSTRAK}

Kartu Kredit adalah alat pembayaran dengan menggunakan kartu, dimana kewajiban pembayaran pemegang kartu dipenuhi terlebih dahulu oleh acquirer atau penerbit kartu yang menggunakan dana pihak ketiga berupa investasi dalam membayar tagihan pemegang kartu. Dana investasi ini yang akan dikelola sebagai penggunaan awal nasabah kartu kredit. Sebagian dari keuntungan yang dihasilkan akan disimpan sebagai simpanan bank sedangkan sebagian lagi digunakan untuk modal bersama dana investasi. Deskripsi tersebut memperlihatkan adanya perputaran uang bank pada sistem kartu kredit yang secara matematis bersesuaian dengan konsep yang direpresentasikan oleh model Kaldor-Kalecki. Dalam penelitian ini perputaran uang tersebut tercermin melalui solusi model tersebut yang diselesaikan secara numerik dengan metode Runge-Kutta. Interpretasi dari solusi numerik model Kaldor-Kalecki pada sistem kartu kredit yang dihasilkan menggunakan data laporan keuangan Bank Mega tahun 2017 memperlihatkan pada tahun tersebut Bank Mega sedang mengalami penurunan jumlah produksi kartu kredit. Oleh karena itu, dapat dikatakan bahwa solusi numerik yang dihasilkan dapat merepresentasikan dengan baik kondisi sistem kartu kredit yang diterbitkan oleh Bank Mega. Nilai negatif pada solusi numerik memperlihatkan perlunya penambahan investasi oleh pihak Bank.

Kata Kunci : Kartu Kredit, Model Kaldor-Kalecki, Metode Runge-Kutta 


\section{PENDAHULUAN}

\subsection{Latar Belakang}

Kartu Kredit adalah alat pembayaran dengan menggunakan kartu yang dapat digunakan untuk melakukan pembayaran atas kewajiban yang timbul dari suatu kegiatan ekonomi, termasuk transaksi pembelanjaan dan/atau untuk melakukan penarikan tunai dimana kewajiban pembayaran pemegang kartu dipenuhi terlebih dahulu oleh acquirer atau penerbit [3]. Bank penerbit kartu kredit menggunakan dana pihak ketiga dalam memenuhi tugasnya untuk melakukan pembayaran terhadap transaksi yang dilakukan oleh pemegang kartu. Salah satu dana pihak ketiga dari bank penerbit adalah investasi. Perputaran uang bank tidak selalu berjalan lancar, hambatan-hambatan yang dialami bank berpengaruh terhadap modal bagi produk bank itu sendiri.

Banyaknya penerbitan kartu kredit bergantung pada banyaknya modal sedangkan banyaknya modal bergantung pada nilai investasi yang diberikan dikurangi dengan nilai penghambat modal. Dari fenomena tersebut dapat dikatakan bahwa penerbitan kartu kredit bergantung pada selisih nilai investasi yang diperoleh dengan keuntungan bank yang harus disimpan menjadi simpanan bank. Sedangkan modalnya bergantung pada selisih nilai investasi dengan nilai penghambat modal bank. Hal ini sama dengan model yang ditawarkan oleh Kaldor-Kalecki. Penelitian ini mengkaji siklus perputaran dana bank pada kartu kredit melalui pendekatan model Kaldor-Kalecki. Model Kaldor-Kalecki yang diterapkan pada masalah kartu kredit, diselesaikan secara numerik menggunakan metode Runge-Kutta. Kemudian dilakukan simulasi menggunakan nilai-nilai parameter terkait untuk melihat dinamika variabel-variabel pembangun model, yaitu produksi dan modal, seiring dengan perubahan waktu.

\subsection{Rumusan Masalah}

Adapun rumusan masalah dari penelitian ini adalah sebagai berikut.

1. Bagaimana persamaan model siklus bisnis perputaran uang bank untuk sistem kartu kredit.

2. Bagaimana penyelesaian numerik sistem kartu kredit melalui model Kaldor-Kalecki dengan metode Runge-Kutta.

3. Bagaimana interpretasi dari solusi numerik model Kaldor-Kalecki pada sistem kartu kredit.

\subsection{Batasan Masalah}

Adapun batasan yang digunakan dalam penelitian ini yaitu sistem kartu kredit yang diteliti adalah sistem kartu kredit yang diterbitkan oleh Bank Mega. 


\section{METODE PENELITIAN}

Penelitian dilakukan sesuai prosedur dibawah ini :

1. Memulai penelitian

2. Mengkaji literatur

3. Mengambil data dari website resmi Bank Mega

4. Menerapkan model Kaldor-Kalecki pada sistem kartu kredit

5. Mendapatkan penyelesaian numerik sistem kartu kredit melalui model Kaldor-Kalecki dengan metode Runge-Kutta

6. Interpretasi hasil penyelesaian numerik model Kalor-Kalecki pada sistem kartu kredit

7. Menyimpulkan hasil penelitian

8. Selesai

III. HASIL DAN PEMBAHASAN

\subsection{Penerapan Model Kaldor-Kalecki Pada Sistem Kartu Kredit}

Proses perputaran uang pada bank untuk sistem kartu kredit yang terdiri dari invetasi, modal, simpanan dan produk dikaji melalui model matematika. Siklus perputaran uang bank pada sistem kartu kredit dimulai dari kegiatan investasi sebagai modal awal untuk menerbitkan kartu kredit. Selanjutnya sebagian keuntungan dari produk tersebut akan disimpan sebagai simpanan bank, dan sisanya akan menjadi modal kembali. Secara matematika, siklus perputaran uang bank pada sistem kartu kredit tersebut digambarkan pada Gambar 1 dan direpresentasikan secara matematis melalui model Kaldor-Kalecki.

Berdasarkan fenomena yang terjadi pada sistem kartu kredit, semakin meningkat nilai investasi $(I)$ dan semakin meningkat modal $(K)$, maka semakin meningkat pula produksi kartu kredit $(Y)$. Keuntungan bank pun akan semakin meningkat, dimana sebagian dari keuntungan ini akan disimpan sebagai simpanan bank $(S)$ dan sisanya akan dikelola bersama dana investasi untuk dijadikan modal. Artinya, Produksi kartu kredit bergantung pada selisih banyaknya nilai investasi dan nilai simpanan. Sedangkan modal pendanaan kartu kredit bergantung pada selisih nilai investasi dan hambatan-hambatan yang dialami bank. Meningkatnya nilai investasi dan menurunnya hambatan-hambatan yang dialami bank akan meningkatkan modal bank terhadap kartu kredit.

Sumber modal terbesar produk-produk bank adalah investasi, begitu pula dengan kartu kredit. Sedangkan sebagian keuntungan yang diperoleh umumnya akan menjadi simpanan bank dan sisanya akan kembali dijadikan modal. Siklus perputaran uang bank pada sistem kartu kredit ini dinyatakan pada Gambar 1. 


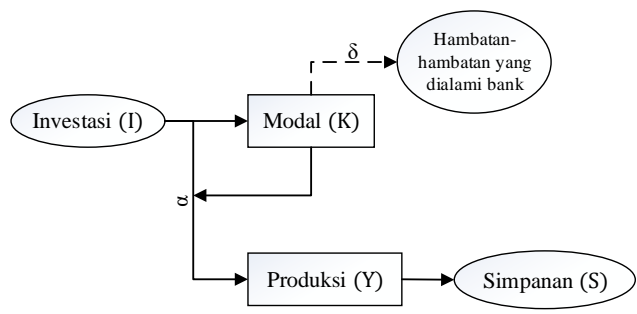

Gambar 1 : Siklus Perputaran Perputaran Uang Bank Pada Sistem Kartu Kredit

Berdasarkan Gambar 1, maka model matematika siklus perputaran uang bank pada sistem kartu kredit dengan waktu tunda yang mengadaptasi model Kaldor-Kalecki adalah sebagai berikut.

$\dot{Y}(t)=\propto[I(Y(t), K(t))-S(Y(t))]$

$\dot{K}(t)=I(Y(t-\theta), K(t-\theta))-\delta K(t)$

Sistem persamaan diferensial non-linier (1) sangat sulit diselesaikan secara eksak, namun dapat diselesaikan menggunakan pendekatan numerik. Salah satu metode numerik yang dapat digunakan adalah metode Runge-Kutta. Asumsikan bahwa sistem autonomous (1) hanya terdiri dari dua fungsi, yaitu $J(Y, K)$ dan $Y$. Maka, $J(Y, K)$ adalah frekuensi rasio produksi dan investasi atau biasa disebut dengan kecenderungan berinvestasi (propensity to invest). Asumsi tersebut menandakan adanya peningkatan pada fungsi modal dari produktifitas, sehingga diperoleh persamaan

$$
J(Y, K)=j(Y / K)
$$

Persamaan (2) dapat dituliskan ke dalam bentuk logaritma seperti berikut ini.

$$
j\left(\frac{Y}{K}\right)=J\left(\frac{Y}{K}\right)=J\left(e^{y-k}\right)=i(y-k)
$$

dimana $y=\log Y$ dan $k=\log K$ dengan $i(y-k)$ fungsi yang menyatakan kecenderungan untuk berinvestasi (propensity to invest) serta $y$ dan $k$ merupakan fungsi terhadap waktu.

Jika fungsi $i(y(t)-k(t))$ didekati menggunakan fungsi logistik dengan menganggap selisih antara produksi dan modal $y(t)-k(t)$ sebagai variabel bebas, maka fungsi tersebut memiliki solusi persamaan seperti berikut.

$$
i(y(t)-k(t))=\frac{a i_{0}}{b i_{0}+\left(a-b i_{0}\right) e^{-a(y(t)-k(t))}}
$$

dalam hal ini fungsi produksi yang dimaksud adalah banyaknya pemegang kartu pada saat $t$.

Investasi berhubungan positif dengan produksi, maka dapat dirumuskan sebagai berikut.

$$
I=i Y
$$

dimana $i$ adalah kecenderungan untuk berinvestasi (propensity to invest). Maka persamaan (5) dapat dituliskan sebagai berikut.

$$
I((Y(t), K(t))=i(y(t)-k(t)) Y(t) .
$$


Fungsi simpanan adalah hasil kali dari kecenderungan untuk menyimpan $(s)$ dengan produksi. Asumsikan bahwa kecenderungan untuk menyimpan (propensity to save) tumbuh berdasarkan logaritma produksi. Maka, fungsi propensity to save dapat dituliskan sebagai berikut.

$$
\begin{gathered}
s(\log Y(t))=s_{0}+s_{1} \log Y(t) \\
s(y(t))=s_{0}+s_{1} y(t) .
\end{gathered}
$$

simpanan ini juga berhubungan positif dengan produksi, yang dirumuskan sebagai berikut.

$$
S=s Y
$$

dimana $s$ adalah kecenderungan untuk menyimpan (propensity to save). Maka persamaan (8) dapat dituliskan sebagai berikut.

$$
S(Y(t))=s(y(t)) Y(t)
$$

Kemudian subsitusikan persamaan (7) ke persamaan (9) sehingga diperoleh,

$$
S(Y(t))=\left(s_{0}+s_{1} y(t)\right) Y(t) .
$$

Selanjutnya, subsitusi persamaan (6) dan persamaan (9) ke persamaan (1) sehingga diperoleh, $\dot{Y}(t)=\propto[i(y(t)-k(t)) Y(t)-s(y(t)) Y(t)]$ $\dot{K}(t)=i(y(t-\theta)-k(t-\theta)) Y(t-\theta)-\delta K(t)$.

Jika pada persamaan tersebut, $\dot{Y}(t)$ dibagi dengan $Y(t)$ dan $\dot{K}(t)$ dibagi dengan $K(t)$, maka akan diperoleh persamaan sebagai berikut.

$$
\begin{aligned}
& \dot{y}(t)=\propto[i(y(t)-k(t))-s(y(t))] \\
& \dot{k}(t)=i(y(t-\theta)-k(t-\theta)) e^{y(t-\theta)-k(t)}-\delta \\
& \operatorname{dimana} \dot{y}(t)=\frac{\dot{Y}(t)}{Y(t)}, \dot{k}(t)=\frac{\dot{K}(t)}{\mathrm{K}(t)}, \quad \operatorname{dan} \frac{Y(t-\theta)}{\mathrm{K}(t)}=e^{y(t-\theta)-k(t)} .
\end{aligned}
$$

Dan jika persamaan (4) dan persamaan (7) disubsitusikan ke persamaan (12), maka akan diperoleh persamaan sebagai berikut.

$$
\begin{aligned}
& \dot{y}(t)=\propto\left[\frac{a i_{0}}{b i_{0}+\left(a-b i_{0}\right) e^{-a(y(t)-k(t))}}-s_{0}+s_{1} y(t)\right] \\
& \dot{k}(t)=\frac{a i_{0}}{b i_{0}+\left(a-b i_{0}\right) e^{-a(y(t-\theta)-k(t-\theta))}} e^{y(t-\theta)-k(t)}-\delta \\
& \text { dimana, } \propto=\text { Koefisien penyesuaian dipasar barang }(\propto>0) \\
& a=\text { Besarnya konsumsi bank terhadap kartu kredit } \\
& b=\text { Marginal Propensity to Consume (MPC) } / \text { besarnya nilai pendapatan } \\
& \text { sebelum dikurangi nilai konsumsi } \\
& i_{0} \quad=\text { besarnya investasi kartu kredit } \\
& s_{0} \quad=\text { besarnya simpanan awal } \\
& s_{1}=\text { besarnya simpanan setelah produksi kartu kredit } \\
& \theta=\text { waktu tunda investasi kartu kredit } \\
& \delta=\text { besarnya dana cadangan kerugian bank }
\end{aligned}
$$




\subsection{Solusi Numerik Model Kaldor-Kalecki Pada Sistem Kartu Kredit}

Pada penelitian ini terdapat parameter $\theta$ yang merupakan waktu tunda untuk fungsi investasi kartu kredit. Waktu tunda tersebut adalah waktu yang dibutuhkan investor untuk memutuskan/melanjutkan investasinya pada kartu kredit bank. Model Kaldor-Kalecki merupakan sistem persamaan diferensial tak linier yang sulit ditentukan solusi eksaknya. Sehingga, model tersebut akan diselesaikan secara numerik menggunakan metode RungeKutta. implementasi formulasi Runge-Kutta tanpa waktu tunda dan dengan waktu tunda dalam siklus perputaran uang bank untuk sistem kartu kredit adalah sebagai berikut.

$$
y(i+1)=y(i)+\frac{1}{6}(k 1 y+2 k 2 y+2 k 3 y+k 4 y)
$$

dengan $k 1 y, k 2 y, k 3 y$ dan $k 4 y$ diperoleh dari persamaan (12) sebagai berikut.

$$
\begin{aligned}
& k 1 y=\left(\propto\left[\frac{a i_{0}}{b i_{0}+\left(a-b i_{0}\right) e^{-a\left(y_{i}-k_{i}\right)}}-s_{0}+s_{1} y_{i}\right]\right)
\end{aligned}
$$

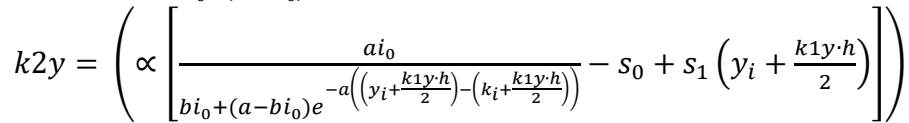

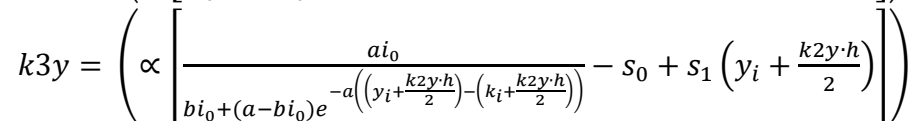

$$
\begin{aligned}
& k 4 y=\left(\propto\left[\frac{a i_{0}}{b i_{0}+\left(a-b i_{0}\right) e^{-a\left(\left(y_{i}+k 3 y \cdot h\right)-\left(k_{i}+k 3 y \cdot h\right)\right)}}-s_{0}+s_{1}\left(y_{i}+k 3 y \cdot h\right)\right]\right) .
\end{aligned}
$$

Dan $k(i+1)=k(i)+\frac{1}{6}(k 1 k+2 k 2 k+2 k 3 k+k 4 k)$

dengan $k 1 k, k 2 k, k 3 k$ dan $k 4 k$ diperoleh dari persamaan (13) sebagai berikut.

$$
\begin{aligned}
k 1 k & =\left(\frac{a i_{0}}{b i_{0}+\left(a-b i_{0}\right) e^{-a(y(t-\theta)-k(t-\theta))}} e^{y(t-\theta)-k(t)}-\delta\right) \\
k 2 k & =\left(\frac{a i_{0}}{b i_{0}+\left(a-b i_{0}\right) e^{-a\left(y\left((i-\theta)+\frac{k 1 k \cdot h}{2}\right)-k\left((i-\theta)+\frac{k 1 k \cdot h}{2}\right)\right.}} e^{y\left((i-\theta)+\frac{k 1 k \cdot h}{2}\right)-k\left(i+\frac{k 1 k \cdot h}{2}\right)}-\delta\right) \\
k 3 k & =\left(\frac{a i_{0}}{b i_{0}+\left(a-b i_{0}\right) e^{-a\left(y\left((i-\theta)+\frac{k 2 k \cdot h}{2}\right)-k\left((i-\theta)+\frac{k 2 k \cdot h}{2}\right)\right.}} e^{y\left((i-\theta)+\frac{k 2 k \cdot h}{2}\right)-k\left(i+\frac{k 2 k \cdot h}{2}\right)}-\delta\right) \\
k 4 k & =\left(\frac{a i_{0}}{b i_{0}+\left(a-b i_{0}\right) e^{-a(y((i-\theta)+(k 3 k \cdot h))-k((i-\theta)+(k 3 k \cdot h)))}} e^{y((i-\theta)+(k 3 k \cdot h))-k(i+(k 3 k \cdot h))}-\delta\right) .
\end{aligned}
$$

Penyelesaian numerik dengan metode Runge-Kutta ini diperoleh dengan menginisialisasi parameter berikut.

Input: $t_{0}=$ batas bawah dari interval waktu

$t_{f}=$ batas atas dari interval waktu

$n$ = banyaknya iterasi

$y_{0} \quad$ (syarat awal untuk produksi)

$k_{0} \quad$ (syarat awal untuk modal)

Output : $y_{i}$ (taksiran nilai $y$ pada iterasi ke- $i$ )

$k_{i}$ (taksiran nilai $k$ pada iterasi ke- $i$ ) 
Langkah selanjutnya adalah menghitung panjang langkah $h=\frac{t_{f}-t_{0}}{n}$ dan inisialisasi syarat awal $y_{1}=y_{0}$ dan $k_{1}=k_{0}$. Kemudian, hitung nilai $y$ dan $k$ untuk $i=1, \ldots, n$. Selanjutnya, perbaharui nilai $y$ dan $k$ dengan formulasi sebagai berikut.

$$
\begin{aligned}
& y(i+1)=y(i)+\frac{1}{6}\left(k_{1 y}+2 k_{2 y}+2 k_{3 y}+k_{4 y}\right) \\
& k(i+1)=k(i)+\frac{1}{6}\left(k_{1 k}+2 k_{2 k}+2 k_{3 k}+k_{4 k}\right) .
\end{aligned}
$$

Setelah itu, tampilkan plot solusi numerik untuk semua $y$ dan $k$ dengan sintaks pada matlab, listing program dapat dilihat pada Lampiran 1. Plot solusi khusus tersebut menggunakan nilai parameter $y_{0}=0.16, k_{0}=8, \propto=0.225, a=8, b=14, i_{0}=2, s_{0}=0.5$ dan $s_{1}=0.6$. Kurva prediksi pertumbuhan produksi dan modal dalam kurun waktu 10 dan 100 tahun dapat dilihat pada Gambar 2 dan Gambar 3.

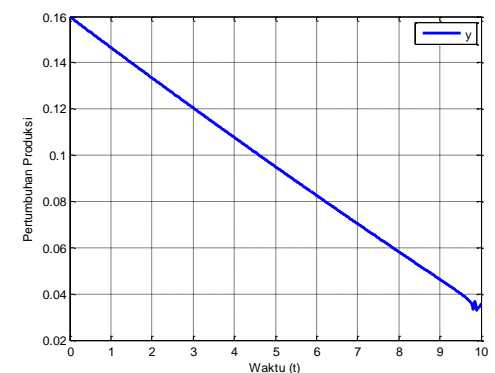

(a)

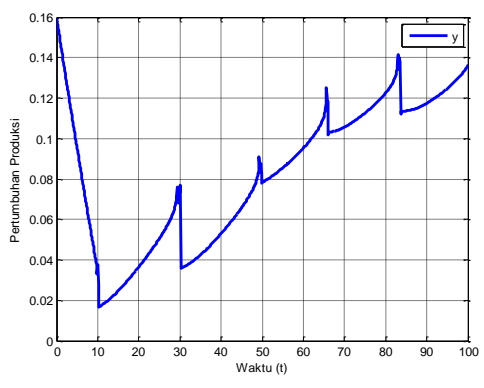

(b)

Gambar 2 : Kurva Prediksi Pertumbuhan Produksi (a) untuk 10 tahun dan (b) untuk 100 tahun

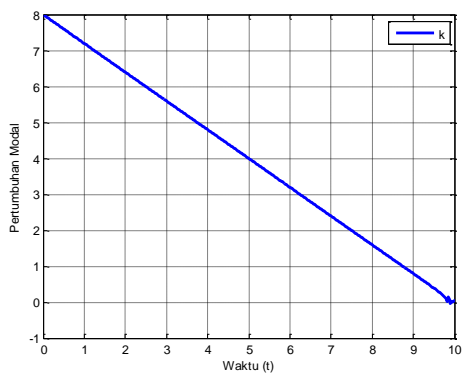

(a)

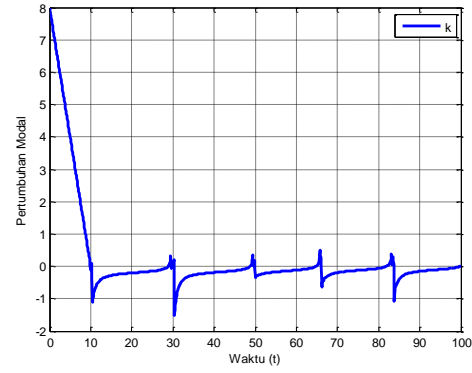

(b)

Gambar 3 : Kurva Prediksi Pertumbuhan Modal (a) untuk 10 tahun dan (b) untuk 100 tahun 


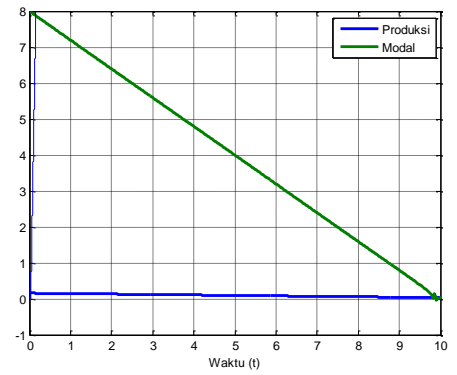

(a)

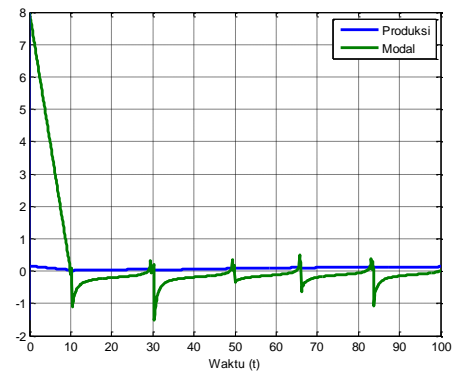

(b)

Gambar 4 : Kurva Prediksi Pertumbuhan Produksi dan Modal (a) untuk 10 tahun dan (b) untuk 100 tahun

\subsection{Pembahasan}

Solusi numerik dari model Kaldor-Kalecki pada sistem kartu kredit yang disajikan pada Gambar 2 dan Gambar 3 menunjukkan jumlah produksi kartu kredit yang terus menurun sedemikian sehingga mengakibatkan jumlah modal produksi kartu kredit juga ikut menurun.

Gambar 2a menunjukkan prediksi pertumbuhan produksi dengan interval waktu selama 10 tahun dengan nilai $n=1000, t_{f}=10$ dan $t_{0}=0$. Gambar tersebut memperlihatkan bahwa pertumbuhan produksi terus menurun hingga tahun ke-10. Faktanya, pada tahun 2018 produksi kartu kredit Bank Mega mengalami penurunan, yaitu dari tahun sebelumnya 1,6 Juta menjadi 1,5 Juta. Sedangkan Gambar 3b menunjukkan prediksi pertumbuhan produksi dengan interval waktu selama 100 tahun dengan nilai $n=1000, t_{f}=100$ dan $t_{0}=0$. Gambar tersebut memperlihatkan pertumbuhan produksi yang turun dari titik awal hingga tahun ke-10, dan setelah itu kurva pertumbuhan produksi bergerak naik turun tak beraturan hingga tahun ke100.

Gambar 3a menunjukkan prediksi pertumbuhan modal dengan interval waktu selama 10 tahun dengan nilai $n=1000, t_{f}=10$ dan $t_{0}=0$. Gambar tersebut memperlihatkan bahwa pertumbuhan modal untuk produksi kartu kredit terus menurun mendekati nol hingga tahun ke10. Sedangkan Gambar 3b menunjukkan prediksi pertumbuhan modal dengan interval waktu selama 100 tahun dengan nilai $n=1000, t_{f}=100$ dan $t_{0}=0$. Gambar tersebut memperlihatkan pertumbuhan modal untuk produksi kartu kredit yang turun dari titik awal menuju nol hingga tahun ke-10, setelah itu kurva pertumbuhan modal bergerak dibawah angka nol.

Solusi tersebut menggunakan data laporan keuangan Bank Mega tahun 2017, dimana pada tahun tersebut, Bank Mega sedang mengalami penurunan jumlah produksi kartu kredit 
akibat pemberlakuan ketetapan Bank Indonesia mengenai pembatasan kepemilikan kartu kredit yang dituangkan dalam Surat Edaran Bank Indonesia Nomor 14/17/DASP. Turunnya jumlah produksi kartu kredit ini pun dirasakan 3 tahun setelah ketetapan tersebut berlaku, yaitu tahun 2016. Oleh karena itu, solusi numerik yang dihasilkan merepresentasikan kondisi sistem kartu kredit yang diterbitkan oleh Bank Mega. Sehingga, berdasarkan kurva pertumbuhan modal yang diperoleh, sangat disarankan untuk Bank Mega menambah jumlah investasinya pada kartu kredit di tahun ke-10.

\section{KESIMPULAN}

Berdasarkan penelitian yang telah dilakukan dapat disimpulkan bahwa :

1. Model siklus perputaran uang bank pada sistem kartu kredit yang mengadaptasi model Kaldor-Kalecki adalah sebagai berikut.

$$
\begin{aligned}
& \dot{y}(t)=\propto\left[\frac{a i_{0}}{b i_{0}+\left(a-b i_{0}\right) e^{-a(y(t)-k(t))}}-s_{0}+s_{1} y(t)\right] \\
& \dot{k}(t)=\frac{a i_{0}}{b i_{0}+\left(a-b i_{0}\right) e^{-a(y(t-\theta)-k(t-\theta))}} e^{y(t-\theta)-k(t)}-\delta
\end{aligned}
$$

2. Solusi numerik dari model siklus perputaran uang bank pada sistem kartu kredit diselesaikan dengan metode Runge-Kutta. Solusi yang dihasilkan berupa skema numerik yang ditunjukkan pada persamaan berikut.

$y(i+1)=y(i)+\frac{1}{6}(k 1 y+2 k 2 y+2 k 3 y+k 4 y)$

dengan :

$k 1 y=\left(\propto\left[\frac{a i_{0}}{b i_{0}+\left(a-b i_{0}\right) e^{-a\left(y_{i}-k_{i}\right)}}-s_{0}+s_{1} y_{i}\right]\right)$

$k 2 y=\left(\propto\left[\frac{a i_{0}}{b i_{0}+\left(a-b i_{0}\right) e^{-a\left(\left(y_{i}+\frac{k 1 y \cdot h}{2}\right)-\left(k_{i}+\frac{k 1 y \cdot h}{2}\right)\right)}}-s_{0}+s_{1}\left(y_{i}+\frac{k 1 y \cdot h}{2}\right)\right]\right)$

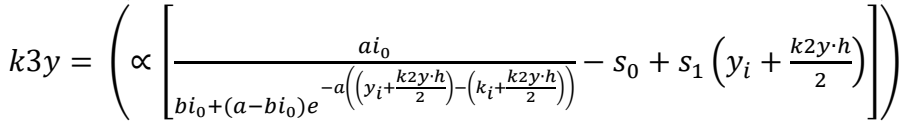

$k 4 y=\left(\propto\left[\frac{a i_{0}}{b i_{0}+\left(a-b i_{0}\right) e^{-a\left(\left(y_{i}+k 3 y \cdot h\right)-\left(k_{i}+k 3 y \cdot h\right)\right.}}-s_{0}+s_{1}\left(y_{i}+k 3 y \cdot h\right)\right]\right)$.

Dan $k(i+1)=k(i)+\frac{1}{6}(k 1 k+2 k 2 k+2 k 3 k+k 4 k)$

dengan :

$$
\begin{aligned}
& k 1 k=\left(\frac{a i_{0}}{b i_{0}+\left(a-b i_{0}\right) e^{-a(y(t-\theta)-k(t-\theta))}} e^{y(t-\theta)-k(t)}-\delta\right) \\
& k 2 k=\left(\frac{a i_{0}}{b i_{0}+\left(a-b i_{0}\right) e^{-a\left(y\left((i-\theta)+\frac{k 1 k \cdot h}{2}\right)-k\left((i-\theta)+\frac{k 1 k \cdot h}{2}\right)\right.}} e^{y\left((i-\theta)+\frac{k 1 k \cdot h}{2}\right)-k\left(i+\frac{k 1 k \cdot h}{2}\right)}-\delta\right) \\
& k 3 k=\left(\frac{a i_{0}}{b i_{0}+\left(a-b i_{0}\right) e^{-a\left(y\left((i-\theta)+\frac{k 2 k \cdot h}{2}\right)-k\left((i-\theta)+\frac{k 2 k \cdot h}{2}\right)\right.}} e^{y\left((i-\theta)+\frac{k 2 k \cdot h}{2}\right)-k\left(i+\frac{k 2 k \cdot h}{2}\right)}-\delta\right) \\
& k 4 k=\left(\frac{a i_{0}}{b i_{0}+\left(a-b i_{0}\right) e^{-a(y((i-\theta)+(k 3 k \cdot h))-k((i-\theta)+(k 3 k \cdot h))}} e^{y((i-\theta)+(k 3 k \cdot h))-k(i+(k 3 k \cdot h))}-\delta\right) .
\end{aligned}
$$


3. Solusi yang diperoleh menggunakan data laporan keuangan Bank Mega tahun 2017, dimana pada tahun tersebut, Bank Mega sedang mengalami penurunan jumlah produksi kartu kredit akibat pemberlakuan ketetapan Bank Indonesia mengenai pembatasan kepemilikan kartu kredit yang dituangkan dalam Surat Edaran Bank Indonesia Nomor 14/17/DASP. Solusi numerik yang dihasilkan merepresentasikan kondisi sistem kartu kredit yang diterbitkan oleh Bank Mega. Kurva pertumbuhan modal yang diperoleh bergerak dibawah angka nol menunjukkan perlunya penambahan jumlah investasinya pada kartu kredit oleh Bank.

4.

\section{DAFTAR PUSTAKA}

[1] Bank Mega, Annual Report Bank Mega 2017, (http://www.bankmega.com/ en/financial_report.php), 2017, Diakses: 28 Desember 2018.

[2] Bank Indonesia, Peraturan Bank Indonesia Nomor 10/8/PBI/2008 Tentang Penyelengaraan Kegiatan Alat Pembayaran Dengan Menggunakan Kartu, (https://www.bi.go.id/), Diakses: 18 Desember 2017.

[3] Rahayu, F., Irmawati dan Hermuningsih, S., Perkembangan Kartu Kredit di Indonesia, Universitas Sarjanawiyata Tamansiswa, 2011, Yogyakarta, Jurnal Manajemen, 1: 5. 